\title{
Clinical and Diagnostic (CT scan) Case Profile of Traumatic Brain Injury (TBI) Patients in a Teritiary Care Center, Visakhapatnam - A Retrospective Observational Study
}

\author{
V. Dharma Rao ${ }^{1}$, Kodandarao Kuna ${ }^{* 2}$, Mohan Patro ${ }^{3}$, Deepak MS. ${ }^{4}$ \\ ${ }^{1}$ Professor \& HOD, Dept. of Orthopedics \& Trauma, King George Hospital- Andhra Medical College, Visakhapatnam \\ ${ }^{2}$ Faculty, Dept. of General Surgery, GIMSR (Gitam Institute of Medical Sciences \& research), Visakhapatnam. Ex I/c \\ Trauma Care Center, King George Hospital, Visakhapatnam \\ ${ }^{3}$ Prof. Dept. of General Surgery, GIMSR (Gitam Institute of Medical Sciences \& research), Visakhapatnam \\ ${ }^{4}$ Consulting Neurosurgeon, GIMSR (Gitam Institute of Medical Sciences \& research), Visakhapatnam
}

Corresponding Author: Dr. Kodandarao Kuna MS(GS)

Flat No. 401, Orchid's Apartment, Ocean View Layout, Pandurangapuram, Visakhapatnam - 530003

Email ID: kkraomsgs@gmail.com

Received 22 April 2019;

Accepted 09 May 2019;

Published 23 May 2019

\begin{abstract}
Introduction: India experiences increase in incidence of Road Traffic Accidents (RTA). During 1970 to 2011, there is 7.3 times increase in road accident injuries. Head injury is the commonest due to RTA injury which accounts for $60 \%$ of cases in Visakhapatnam which is situated along the ${ }^{9}$ National Highway. Aim: The aim is to study the clinical and CT scan diagnostic case profile of Traumatic brain injury (TBI) in Visakhapatnam region. Material \& Methods: It is a retrospective observational study of cases of TBI reported at the trauma care center at the tetitiary care King George Hospital (KGH), Visakhapatnam, for the period 2011 - 2018. Proper permission and clearance for the present study is duly obtained. Results \& Discussion: Head injury is the commonest among traumatic injuries. CT scan is performed as the gold standard diagnostic test for head injury cases. Contusions followed by Sub arachnoid hemorrhage (SAH) and Sub dural hemorrhage (SDH) are the most common CT findings. About 25\% needed ventilator support. Most common cause of death is CNS injuries (42\%) followed by blood loss in $39 \%$ of cases. Conclusions: Regulated traffic control, wearing helmet and seat belt, limiting speed and avoiding L \& U bends at road corners can prevent and minimise the incidence of fatal injuries.
\end{abstract}

Keywords: RTA, TBI, injuries, CT scan brain, case

\section{Introduction and Statistics}

Definition of ${ }^{4}$ TBI: TBI is a non degenerative, non congenital insult to the brain from an external physical force, possibly leading to permanent or temporary impairment of cognitive, physical and psychological functions with an associated diminished or altered state of consciousness. Glasgow coma scale classifies TBI severity and grades the serious level of consciousness on a scale of $3-15$ based on verbal, motor and eye opening reactions to stimuli.

Primary mechanical injury: Translational acceleration causes focal hemorrhagic contusions which largely involve the frontal and temporal lobes (EDH \& SDH). Rotational acceleration causes diffuse shearing stretch of axonal and vascular cell membranes.
${ }^{18,19}$ Glasgow coma scale (GCS): was introduced by Teasdale \& Bennett in 1974 is the best initial measure of severity of head injury. TBI is mild if score is $13-15$, moderate if 9-12, severe if 38. PTA: is post traumatic amnesia, patients are confused and disoriented, duration of PTA and not retrograde amnesia is the useful predictor of outcome. Imaging: Difficult to perform ${ }^{8} \mathrm{MRI}$ scan in acute state. Imaging can't predict the outcome but GCS can. ${ }^{23}$ Injury severity score(ISS) is based on the body anatomic regions affected and predicts outcome.In the trimodal distribution, the first golden hour deaths are due to cardiorespiratory arrest. Most of the deaths due to head injury (TBI) are due to SDH, EDH and Hemothorax. EDH is supratentorial in $95 \%$ cases and is associated with skull bone fracture in $90 \%$ of cases, $>30 \mathrm{~cm}$ on CT has to be operated. SDH is the most common TBi with $60-80 \%$ 
of mortality, and in $30-50 \%$ of cases pupils are affected, lesion > $10 \mathrm{~mm}$ has to be operated, and presents with cresent haematoma on CT scan. DAI is caused in high velocity RTA and ${ }^{8} \mathrm{MRI}$ is better diagnostic. Adam's grading $1-3$ is applied. Secondary brain injuries are edema, infarction and herniation

RTAs accounts for major share in TBI in India. During 1970 to 2011, there is 7.3 times increase in road accident injuries. As a result, a large number of individuals with TBI endure life-long impairment and disability. It was estimated that the total costs of road traffic injuries alone is about 55,000 crore a year in India. As per national crime records bureau of Delhi, India maximum number of RTA cases occur between the age group 15-44 years. ${ }^{3}$ Helmet \& ${ }^{30,31}$ Seat belt injuries: In an individual with seat-belt during impact, violent deceleration of human body occurs. Seatbelt impinges heavily on its point of contact with trunk and viscera continue to move forward. As per Amritsar study by Tejender Singh in 2012, only $12.08 \%$ used helmet, $23.61 \%$ used seat belt and as per ${ }^{2,15}$ New Delhi study by Puneet Mishra in the 2011, about $63.3 \%$ not used helmet and $32.3 \%$ not used seat belt.

${ }^{13,14}$ INDIAN SCENARIO: The increase in economic growth in India coupled with rise in population, motorization and industrialization have contributed to a significant increase in TBI with each advancing year. An epidemiological study in ${ }^{6,7}$ Bangalore in the year 2012 indicates that the incidence, mortality and case fatality rates were $150 / 1,00,000,20 / 1,00,000$ and $10 \%$, respectively.

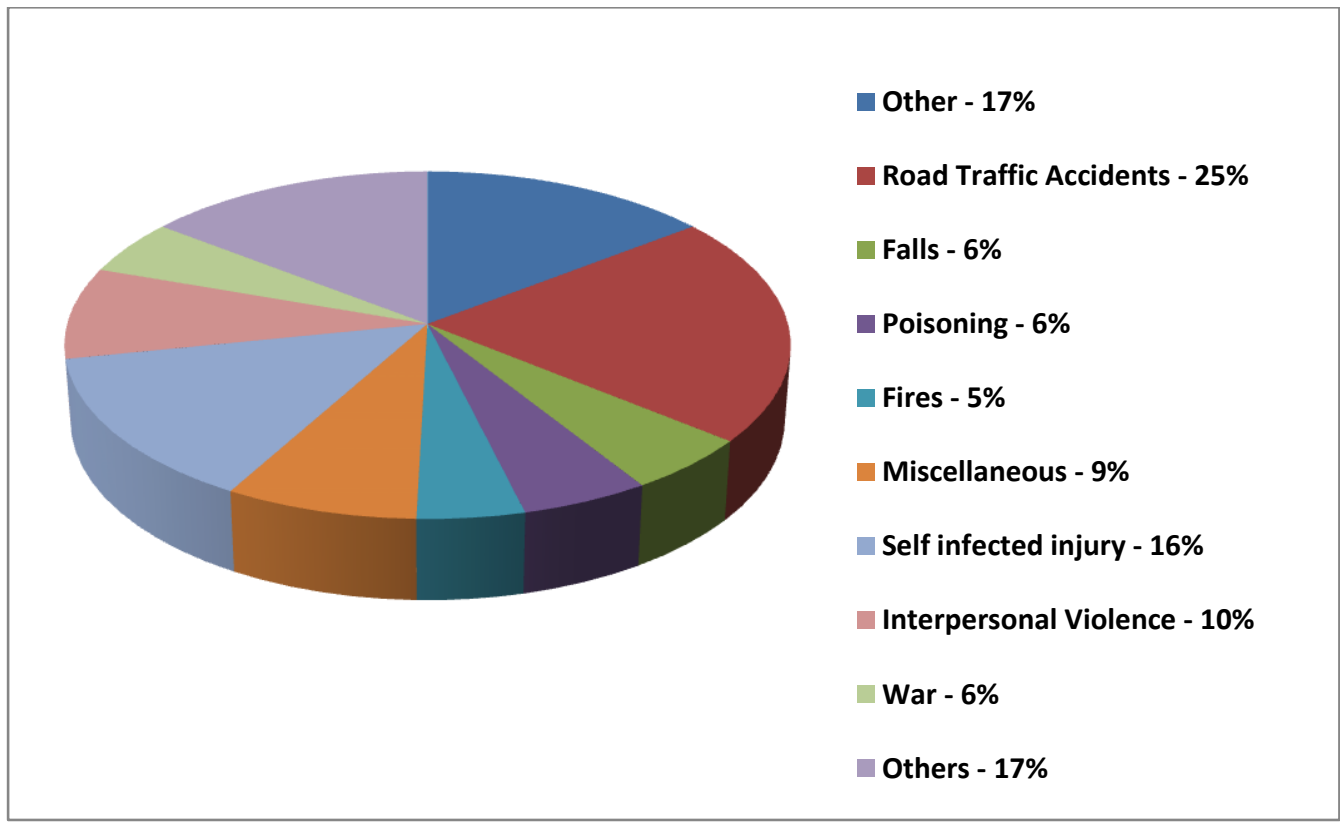

${ }^{12}$ Diagram 1: As per WHO report above the most common cause of trauma is RTA.

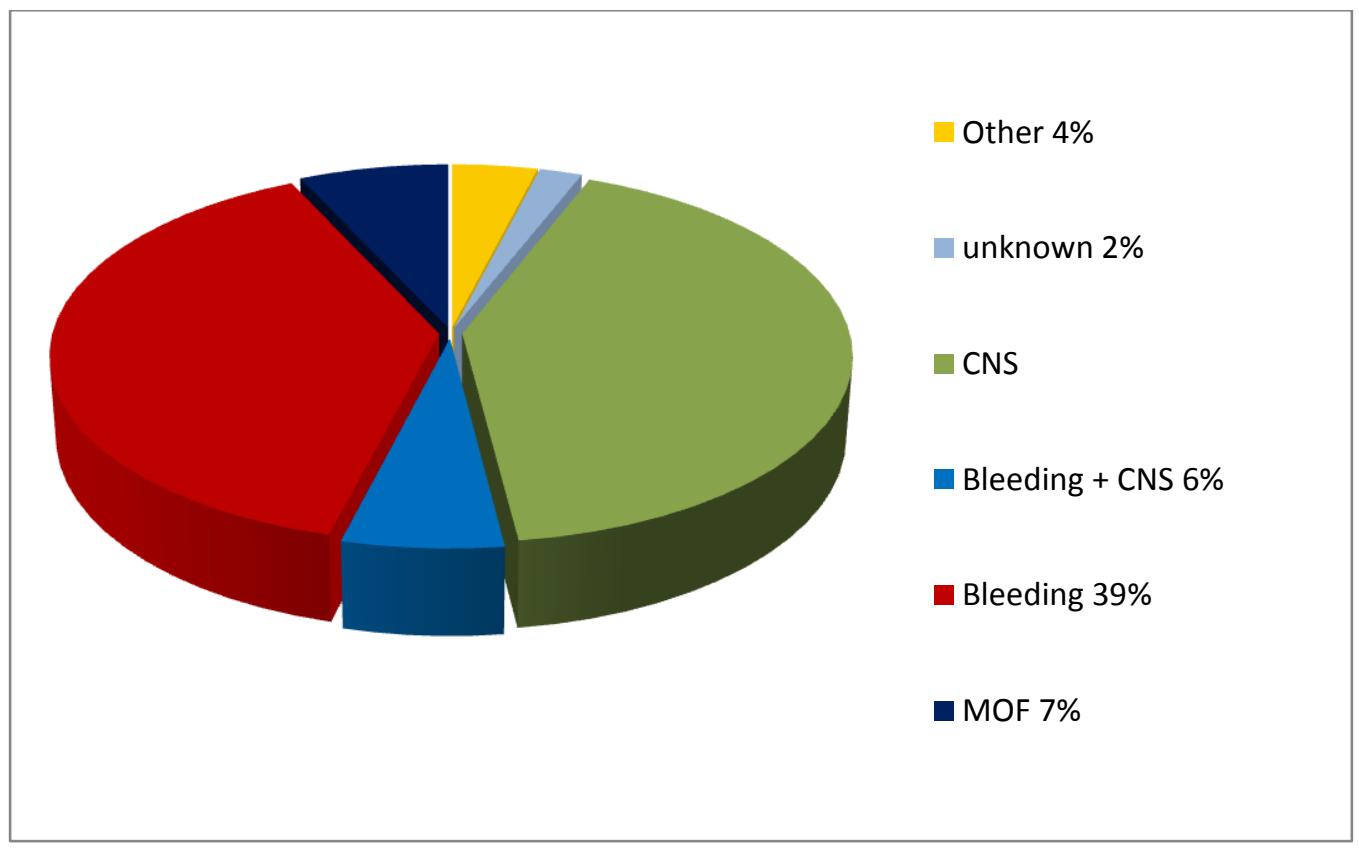

Diagram 2: Causes of Death 5 - Usa Experience

CNS - 42\%, Bleeding - 39\% 


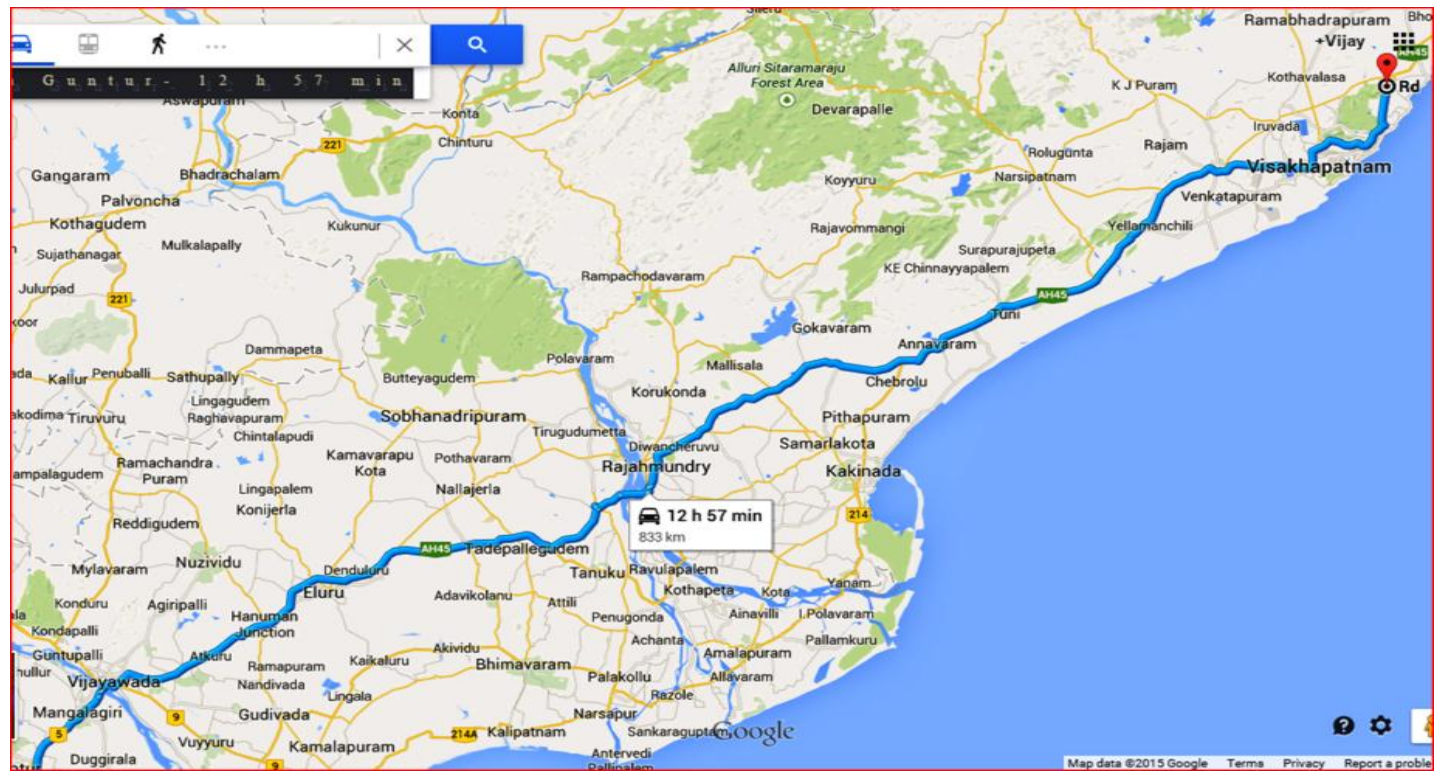

National highway 5 passing through AP state - Trauma Care Centers in Green Circle

\section{Material \& Methods}

The source of the data for the present study is the clinical case material of trauma victims reported at the casualty dept. of $\mathrm{KGH}$, Visakhapatnam for the period of Jan 2011 to Dec 2018 recorded at the data entry center of trauma care center. Of the total OP trauma cases of 71,857, screened, 6532 are IP admissions. However, deaths are calculated from OP and IP data.

Methodology: Study design and setting - The original research work is done at the research centre, GIMSR (Gitam Institute of Medical Sciences and Research), A Deemed to be University, Visakhapatnam, AP. The data is collected from the trauma care center, KGH with permission and clearance. The data is spread over the excel sheet and tabulated and applied SPSS software.
Statistical illustrations are given. Informed consent is taken from the patients wherever relevant. It is a retrospective observational study

TRAUMA CARE FACILITY AT KING GEORGE HOSPITAL(KGH), VISAKHAPATNAM, AP: The dedicated traumacare center is a 30 bedded ward with 6 bed ICU, 6 ventilators $\&$ multi channel monitors, transport ventilator, central oxygen \& suction, neuro anaesthesia, Craniotome and drills, Carm, Bipolar cautery, Pressure gradient suction apparatus, Microsurgical instruments, Haemostatic agents and dural patches and trained staff for traumacare, ICU and OT apart from the availability of specialist doctors like neurosurgeons, orthopaedcians and general surgeons round the clock. CT scan is attached to the center.

Table 1: Trauma - RTA Case Profile Statistics - 2011 To 2018

\begin{tabular}{|l|l|l|l|l|l|l|l|l|l|}
\hline YEAR & $\mathbf{2 0 1 1}$ & $\mathbf{2 0 1 2}$ & $\mathbf{2 0 1 3}$ & $\mathbf{2 0 1 4}$ & $\mathbf{2 0 1 5}$ & $\mathbf{2 0 1 6}$ & $\mathbf{2 0 1 7}$ & $\mathbf{2 0 1 8}$ & TOTAL \\
\hline O.P. & 8246 & 8554 & 8710 & 8424 & 9425 & 10191 & 9885 & 8422 & 71857 \\
\hline I.P. & 662 & 736 & 640 & 797 & 802 & 971 & 1142 & 782 & 6532 \\
\hline I.P \% & 8.03 & 8.60 & 7.35 & 9.46 & 8.51 & 9.53 & 11.55 & 9.29 & $9.04 \%$ \\
\hline MALE & 544 & 588 & 503 & 650 & 637 & 833 & 888 & 651 & 5294 \\
\hline FEMALE & 118 & 148 & 137 & 147 & 165 & 138 & 254 & 131 & 1238 \\
\hline M/F RATIO & 4.61 & 3.97 & 3.67 & 4.42 & 3.86 & 6.04 & 3.50 & 4.97 & 4.38 \\
\hline DISCHARGE & 4 & 0 & 2 & 31 & 17 & 127 & 23 & 7 & 211 \\
\hline LAMA & 97 & 108 & 74 & 99 & 88 & 114 & 85 & 52 & 717 \\
\hline SHIFT & 250 & 265 & 243 & 330 & 410 & 436 & 770 & 508 & 3212 \\
\hline RTA & 404 & 388 & 359 & 453 & 490 & 493 & 543 & 321 & 3451 \\
\hline FALLS & 179 & 184 & 142 & 198 & 204 & 387 & 535 & 426 & 2255 \\
\hline ASSAULT & 12 & 25 & 16 & 21 & 14 & 29 & 28 & 20 & 165 \\
\hline MLC & 550 & 598 & 517 & 686 & 766 & 954 & 1139 & 773 & 5983 \\
\hline NON-MLC & 112 & 138 & 123 & 114 & 36 & 17 & 3 & 9 & 552 \\
\hline CONSERVATIVE & 530 & 515 & 434 & 638 & 673 & 841 & 994 & 662 & 5287 \\
\hline SURGICAL & 132 & 221 & 206 & 159 & 129 & 130 & 148 & 120 & 1245 \\
\hline HEAD INJURY & $\mathbf{6 2 2}$ & $\mathbf{6 8 2}$ & $\mathbf{5 9 0}$ & $\mathbf{7 2 1}$ & $\mathbf{7 2 2}$ & $\mathbf{8 2 2}$ & $\mathbf{9 1 4}$ & $\mathbf{6 5 0}$ & $\mathbf{5 7 2 3}$ \\
\hline SPINE INJURY & 30 & 43 & 39 & 36 & 24 & 24 & 80 & 58 & 334 \\
\hline POLY TRAUMA & 154 & 153 & 81 & 112 & 98 & 169 & 192 & 123 & 1082 \\
\hline DEATHS & 311 & 363 & 321 & 337 & 287 & 294 & 264 & 215 & 2392 \\
\hline
\end{tabular}

LAMA - Left Against Medical Advise.

RTA - Road Traffic Accident

MLC - Medico Legal Case 
In the present study RTA constitute about $58 \%$ of the total IP trauma cases. Head injury constitutes $87.61 \%$ of the total RTA. Death rate is $3.33 \%$ of the total OP trauma cases reported.

Table 2: CT Brain - TBI - Findings - Area of brain affected - analysis of 552 cases for the year 2018

\begin{tabular}{|c|c|c|c|c|c|c|}
\hline \multicolumn{2}{|l|}{ Area } & Contusion & EDH & SDH & SAH & Total \\
\hline \multirow{3}{*}{ Frontal } & Right & 39 & 10 & 7 & & 56 \\
\hline & Left & 39 & 7 & 6 & 1 & 53 \\
\hline & Un-Sp & 34 & 1 & 4 & & 39 \\
\hline \multirow{4}{*}{ Parietal } & Right & 5 & 10 & 3 & 1 & 19 \\
\hline & Left & 13 & 3 & 3 & 1 & 17 \\
\hline & High Parietal & & 8 & 1 & & 11 \\
\hline & Un-Sp & 7 & & 2 & & 7 \\
\hline \multirow{3}{*}{ Temporal } & Right & 29 & 7 & 4 & 1 & 41 \\
\hline & Left & 46 & 4 & 3 & 4 & 57 \\
\hline & Un-Sp & 5 & 11 & & & 16 \\
\hline \multirow{3}{*}{ Occiptal } & Right & & 2 & & & 2 \\
\hline & Left & 2 & 1 & & & 3 \\
\hline & Un-Sp & 1 & 1 & & & 2 \\
\hline \multirow{3}{*}{ Fronto-Parietal } & Right & 3 & 1 & 3 & & 7 \\
\hline & Left & 3 & 2 & 3 & & 8 \\
\hline & Un-Sp & 2 & & & & 2 \\
\hline \multirow{3}{*}{ Fronto-Temporal } & Right & 4 & 2 & 5 & 3 & 14 \\
\hline & Left & 7 & 2 & 5 & 2 & 16 \\
\hline & Un-Sp & & & & & \\
\hline \multirow{3}{*}{ Parieto-Occiptal } & Right & & 1 & & & 1 \\
\hline & Left & & & & & \\
\hline & Un-Sp & 2 & & & & 2 \\
\hline \multirow{3}{*}{ Temporo-Occipital } & Right & & & & & \\
\hline & Left & 1 & & & & 1 \\
\hline & Un-Sp & & & & & \\
\hline \multirow{3}{*}{ Temporo-Parietal } & Right & & 3 & 7 & & 10 \\
\hline & Left & & 9 & 9 & 2 & 20 \\
\hline & Un-Sp & & 1 & & & 1 \\
\hline \multirow{3}{*}{ Fronto-Temporo-Parietal } & Right & 28 & & 27 & 3 & 58 \\
\hline & Left & 40 & & 36 & 3 & 79 \\
\hline & Un-Sp & 4 & & 4 & 2 & 10 \\
\hline \multicolumn{2}{|l|}{ Total: } & 314 & 86 & 132 & 23 & 552 \\
\hline
\end{tabular}

Brain stem - 23 contusions, 1 SDH, Cerebral - 1, Cord - 2 contusions, Ventricular - 1, Others - 97, Total $-125 \ldots$ Grand total $-552+125=677$. Frontal area is affected most often (148), followed by temporal (114). Hence, frontal impact injuries are significant in TBI.

As per the data of the CT brain findings, contusions are 314 out of 552 scans amounting to $56.88 \%$ i.e., about half of all the CT brain scans. Frontal and fronto-temporal take the lot among contusions. Next comes SDH and SAH in equal proportion. Front impact injuries are more common than side impact injuries.

Table 3: CT scan brain diagnostic - surgical pathology of head injury: 2011 - 2018

\begin{tabular}{|c|c|c|c|c|c|c|c|c|c|}
\hline Year & Contusion & $\begin{array}{c}\text { Sub Arachnoid } \\
\text { Haege }\end{array}$ & $\begin{array}{c}\text { Sub } \\
\text { Dural } \\
\text { Haege }\end{array}$ & $\begin{array}{l}\text { Extra } \\
\text { Dural } \\
\text { Haege }\end{array}$ & $\begin{array}{l}\text { Diffuse } \\
\text { Axonal } \\
\text { Injury }\end{array}$ & Quadriplegia & $\begin{array}{c}\text { Obstructive } \\
\text { Hydrocephalus }\end{array}$ & $\begin{array}{l}\text { Mass } \\
\text { Effect }\end{array}$ & $\begin{array}{c}\text { Mildline } \\
\text { Shift }\end{array}$ \\
\hline 2011 & 105 & 187 & 104 & 86 & 52 & 24 & 6 & 12 & 3 \\
\hline 2012 & 262 & 223 & 155 & 72 & 16 & 29 & 30 & 34 & 52 \\
\hline 2013 & 268 & 128 & 159 & 88 & 35 & 20 & 29 & 31 & 87 \\
\hline 2014 & 316 & 183 & 165 & 92 & 56 & 10 & 30 & 19 & 94 \\
\hline 2015 & 331 & 203 & 203 & 103 & 110 & 5 & 10 & 37 & 80 \\
\hline 2016 & 378 & 210 & 182 & 111 & 92 & 6 & 4 & 47 & 113 \\
\hline 2017 & 385 & 255 & 187 & 129 & 42 & 31 & 1 & 101 & 214 \\
\hline 2018 & 299 & 144 & 163 & 86 & 44 & 21 & 2 & 57 & 94 \\
\hline TOTA: & 2344 & 1533 & 1318 & 767 & 447 & 146 & 112 & 338 & 737 \\
\hline
\end{tabular}

Hematoma - 125, Intra Cerebral Haege - 4, No Injury on CT - 123. Total -7742(both IP \& OP) 
As per the data in the table above the commonest CT Brain finding is contusion followed by sub arachnoid haemorrhage (SAH) and later sub dural haemorrhage(SDH). About $10 \%$ have mid line shift and about 5.8\% are cases of diffuse axonal injury which are of poor prognostic concern. SAH, SDH and EDH constitute about $50 \%$ of cases of head injury as per CT findings.

Table 4: Bhopal study

\begin{tabular}{|l|l|l|l|l|} 
Distribution of RTA cases according to type of injury - study by Khare Neeraj, Bhopal from Jan 2009 - Oct 2011 of 1268 cases \\
\hline Types of Injury & $\mathbf{2 0 0 9}$ & $\mathbf{2 0 1 0}$ & $\mathbf{2 0 1 1}$ & Total \\
\hline Head Injury & $236(58.3)$ & $252(56.6)$ & $237(56.7)$ & $752(59.3)$ \\
\hline Fracture of Upper Limb & $86(21.2)$ & $98(22)$ & $86(20.6)$ & $270(21.3)$ \\
\hline Fracture of Lower Limb & $58(14.3)$ & $55(12.4)$ & $61(2)$ & $174(13.7)$ \\
\hline Chest Injury & $15(3.7)$ & $23(5)$ & $18(4.3)$ & $56(4.4)$ \\
\hline Others (Rib+Vertebra) & $10(2.5)$ & $17(3.8)$ & $16(3.8)$ & $43(3.3)$ \\
\hline Total & $\mathbf{4 0 5}(\mathbf{1 0 0})$ & $\mathbf{4 4 5 ( 1 0 0 )}$ & $\mathbf{4 1 8}(\mathbf{1 0 0})$ & $\mathbf{1 2 6 8 ( 1 0 0 )}$ \\
\hline
\end{tabular}

It was observed that head injury was most common (59.3\%) injury among RTA victims followed by fracture of upper limb (21.3\%) \& lower limb $174(13.7 \%)$ respectively similar observation were reported in studies from Karnataka out of 360 RTA cases $156(43.32 \%)$ had head injury.

Table 5: Head injury (tbi) related personal factors of victims

\begin{tabular}{|c|c|c|c|c|c|c|c|}
\hline FACTORS & YEAR & 2010 & 2011 & 2012 & 2013 & 2014 & 2015 \\
\hline \multirow{4}{*}{$\begin{array}{l}\text { PROTECTIVE } \\
\text { DEVISES }\end{array}$} & HELMET USED & 32 & 27 & 21 & 0 & 1 & 10 \\
\hline & HELMET NOT USED & 136 & 160 & 201 & 265 & 490 & 348 \\
\hline & SEAT BELT USED & 9 & 6 & 5 & 0 & 0 & 7 \\
\hline & SEAT BELT NOT USED & 95 & 53 & 61 & 375 & 222 & 45 \\
\hline \multirow{2}{*}{ INTOXICATION } & ALCOHOL CONSUMED & NA & NA & NA & $149(23.28 \%)$ & $133(16.69 \%)$ & $226(28.17 \%)$ \\
\hline & ALCOHOL NOT CONSUMED & NA & NA & NA & $491(76.72 \%)$ & $664(83.31 \%)$ & $576(71.82 \%)$ \\
\hline \multirow{2}{*}{ STATUS OF PATIENT } & CONSCIOUS & 197 & 234 & 128 & 88 & 114 & 65 \\
\hline & UN-CONSCIOUS & 399 & 419 & 470 & 550 & 683 & 734 \\
\hline \multirow{2}{*}{ LIFE SUPPORT } & VENTILATOR NEEEDED & 197 & 174 & 151 & 98 & 156 & 90 \\
\hline & VENTILATOR NOT NEEDED & 404 & 488 & 457 & 542 & 557 & 712 \\
\hline
\end{tabular}

\section{Brought Dead 31 Patients}

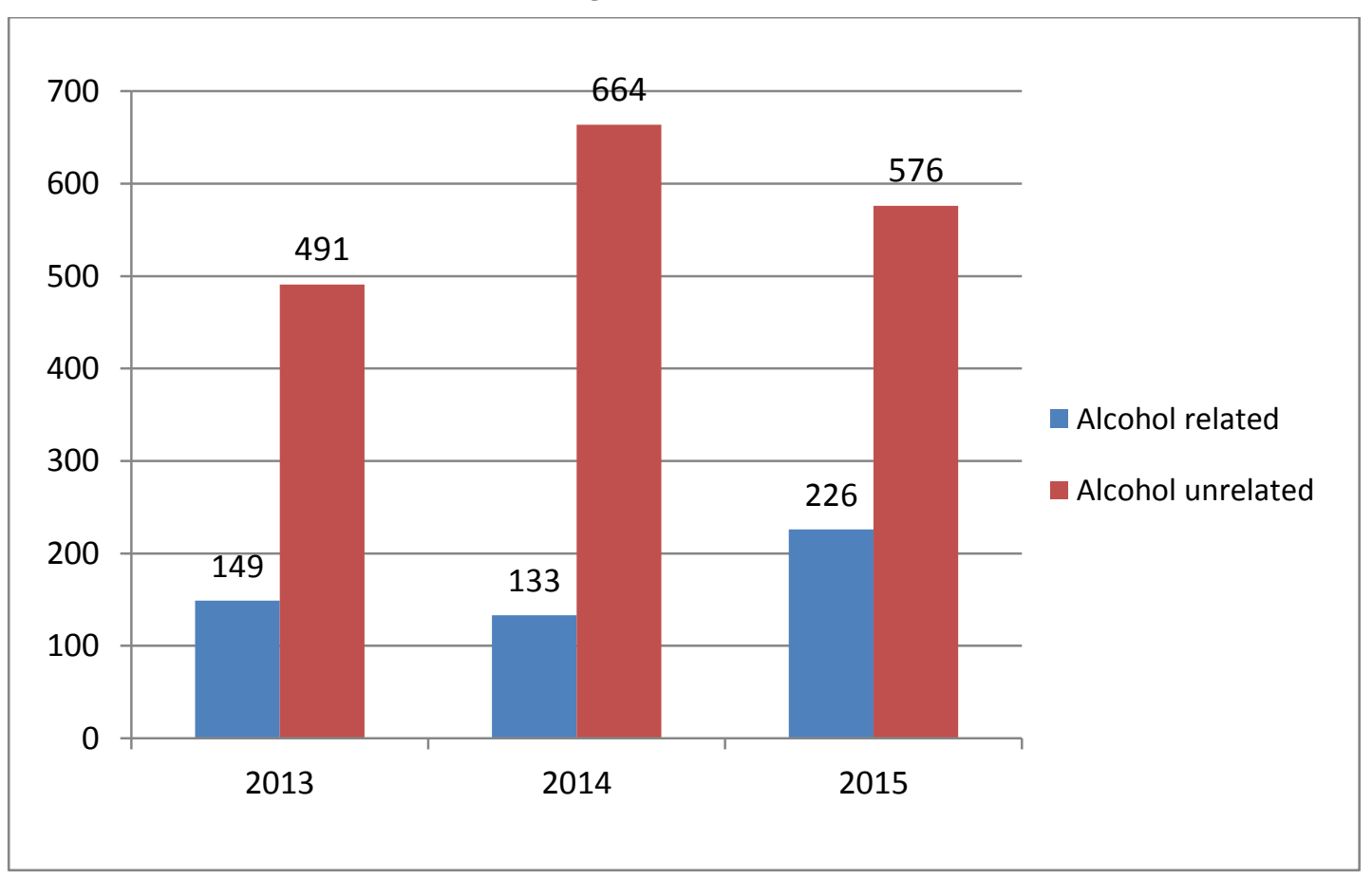

Diagram: 3 


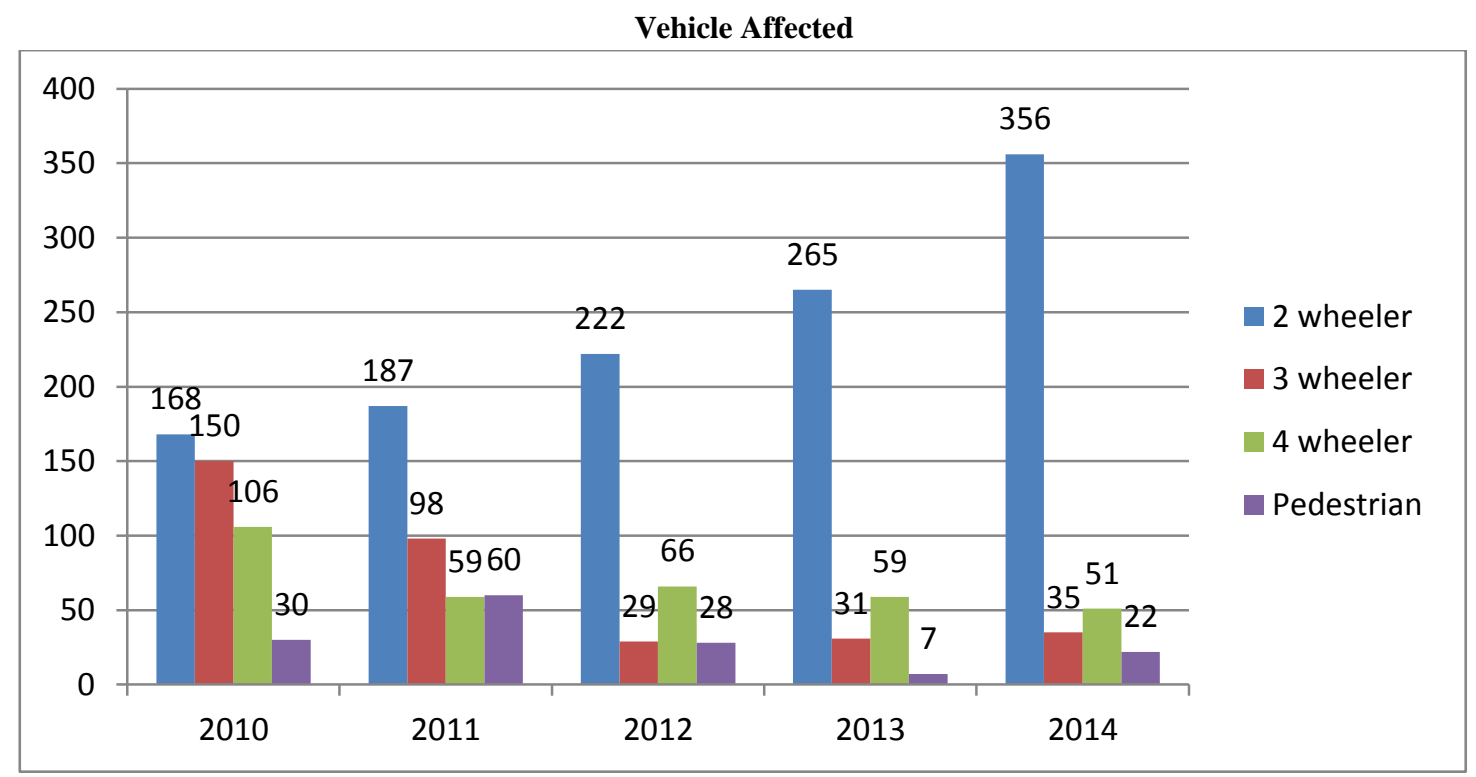

Diagram: 4

Protective devices used

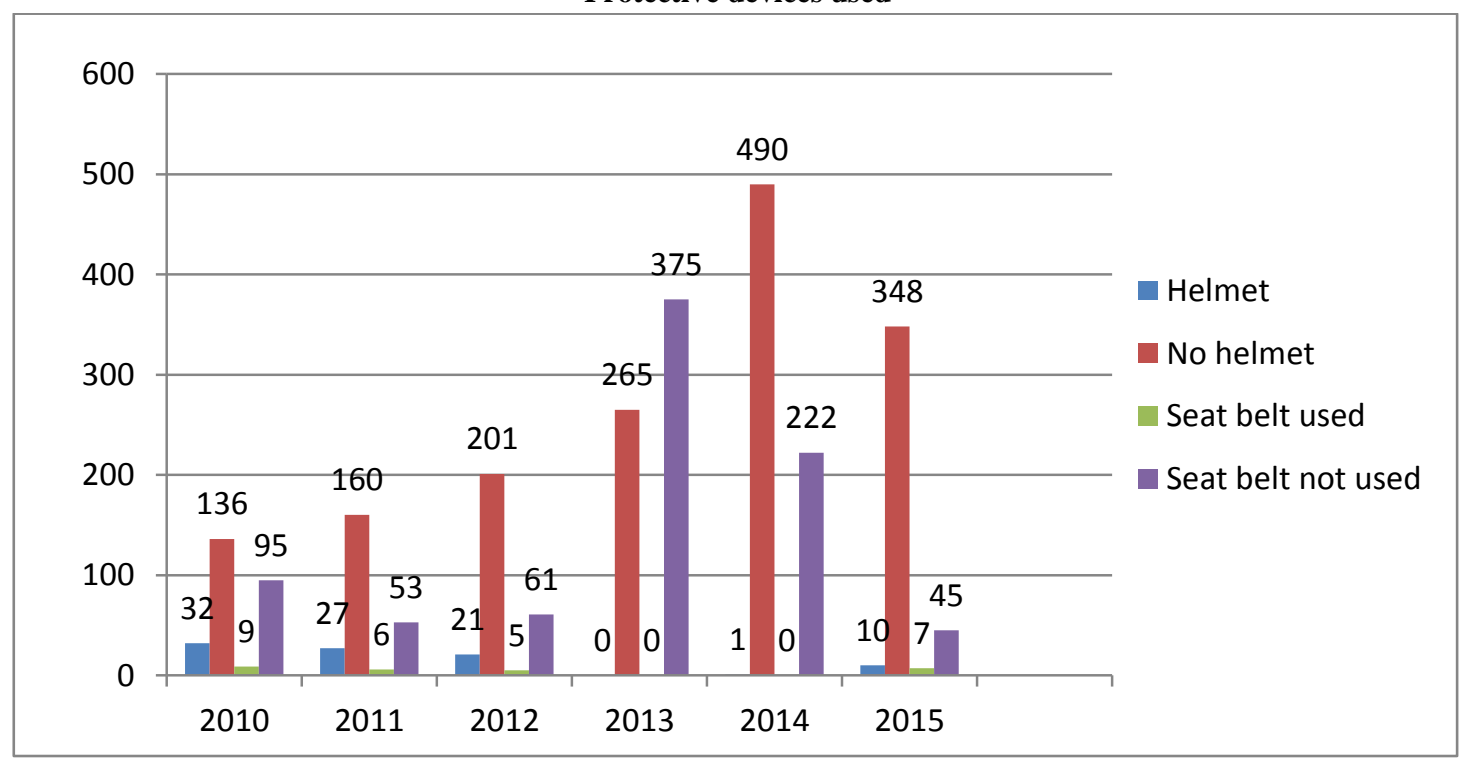

Diagram: 5

Only $3.54 \%$ (91) used helmet and 1\% (27) used seat belt out of 2569 cases studied.

Pathology Wise

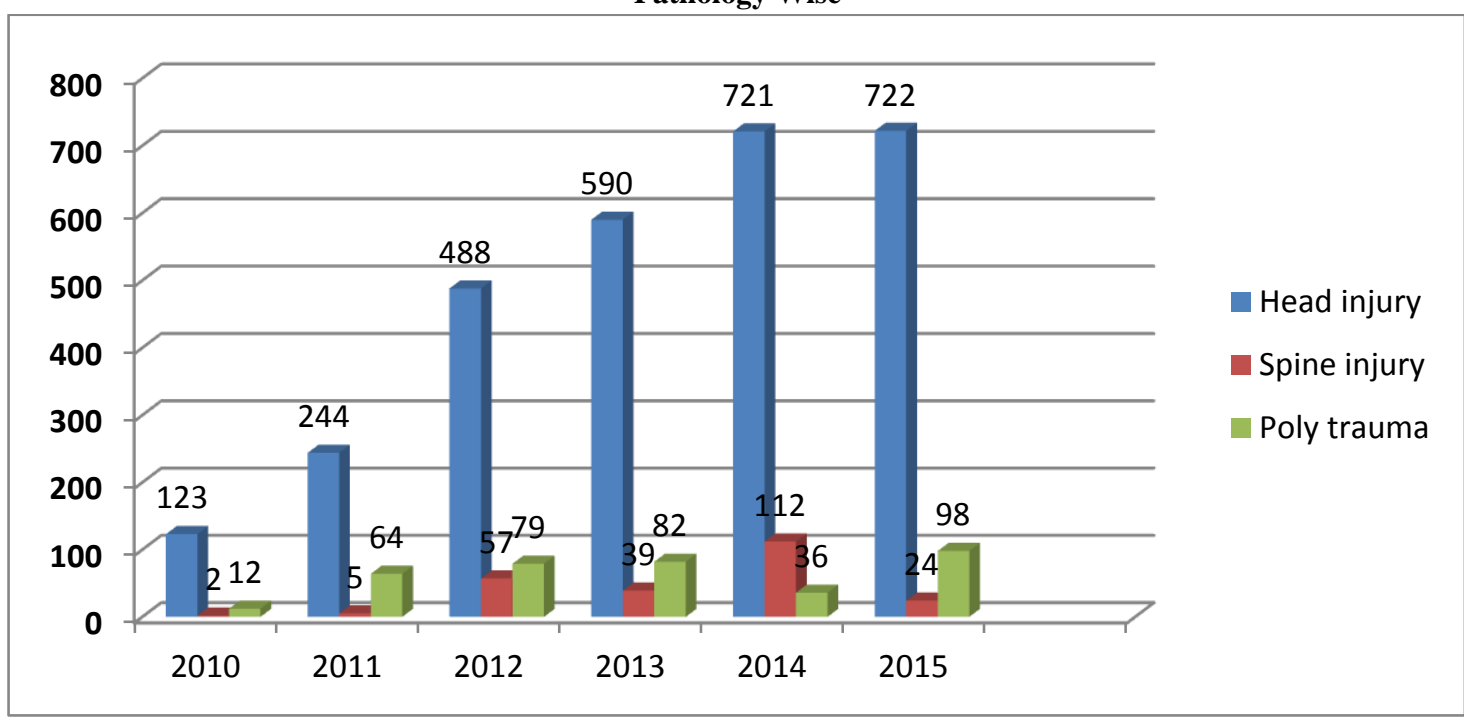

Diagram: 6 


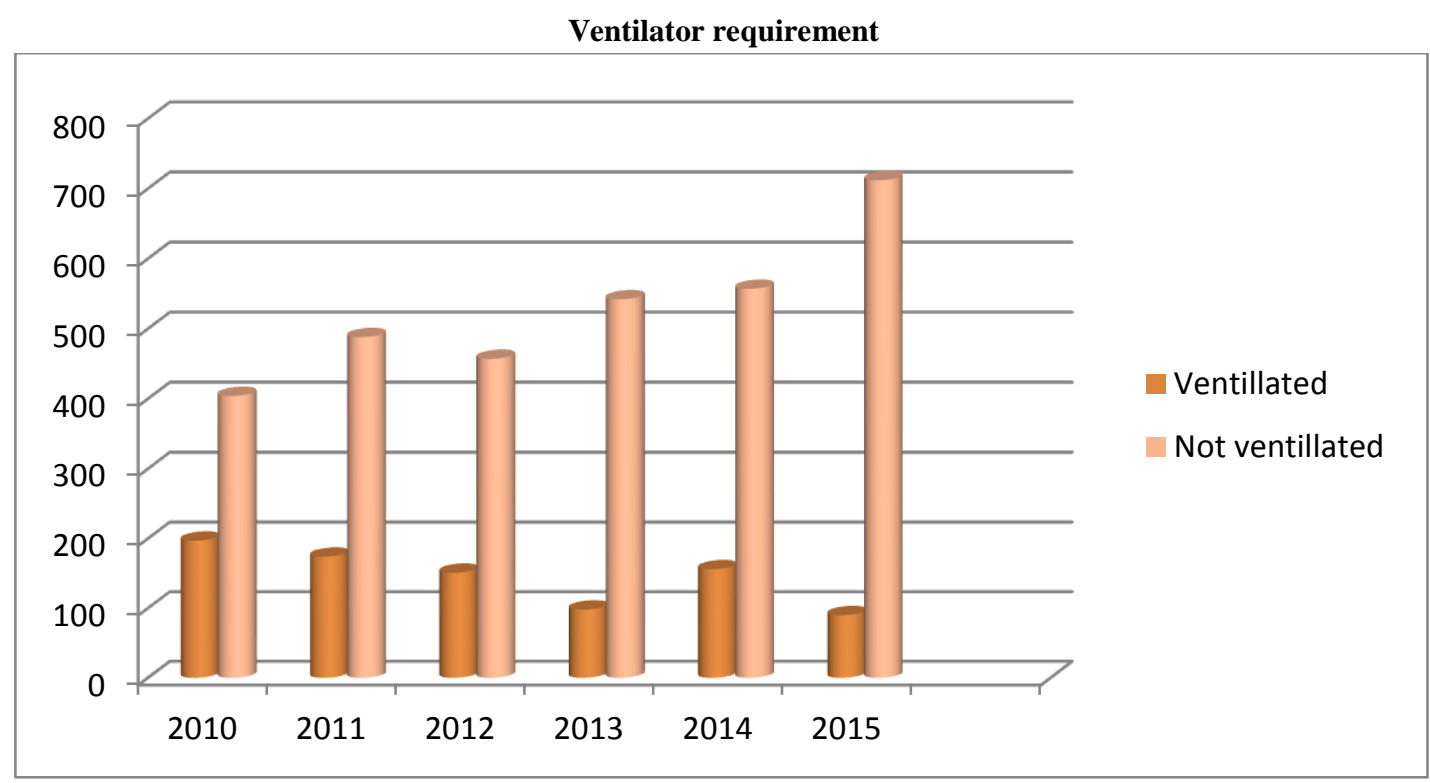

Diagram: 7

About 1/4th (25.76\%-882) of patients (3423) needed ventilator support.

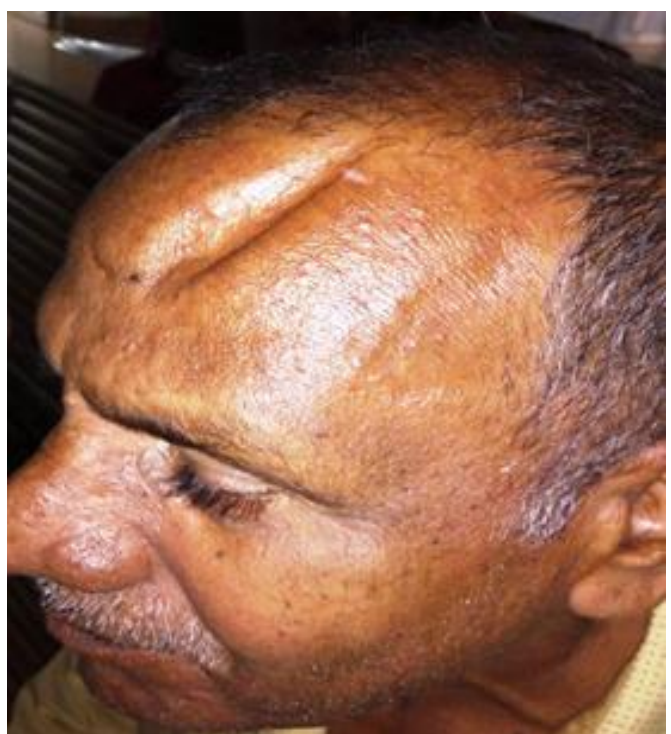

Image: 1

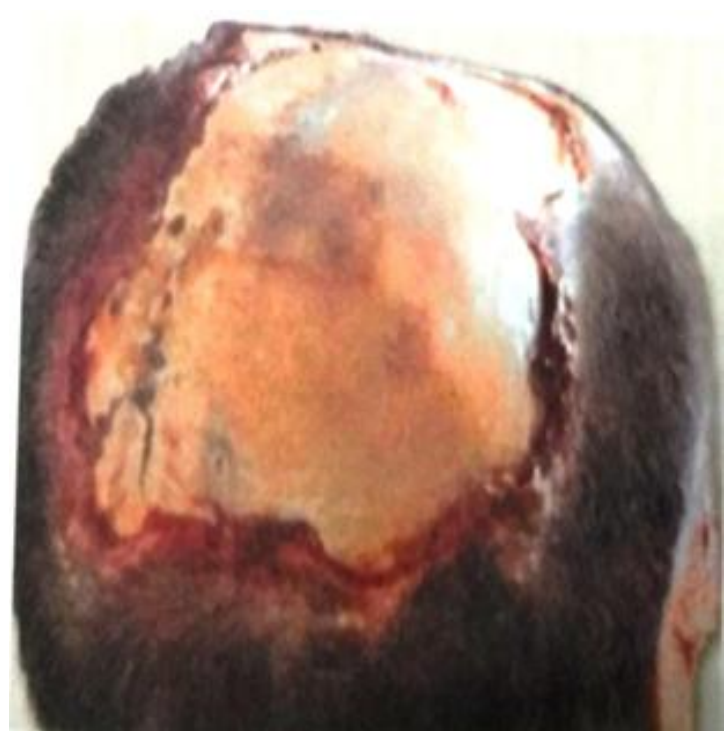

Image: 2

Gutter (depressed) fracture - neglected but healed. Degloving injury scalp exposing the cranial bone (sequestrated):

Depressed Fractures Acute Epidural Haematoma

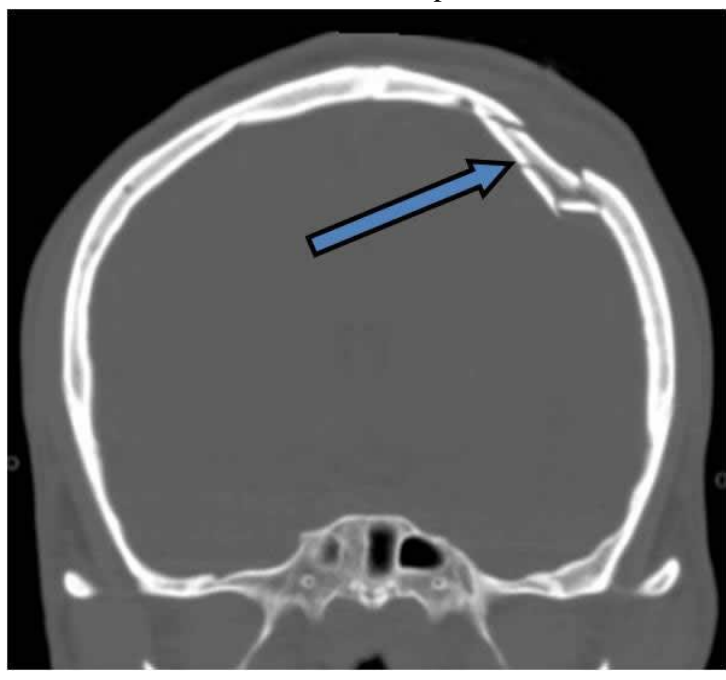

Image: 3

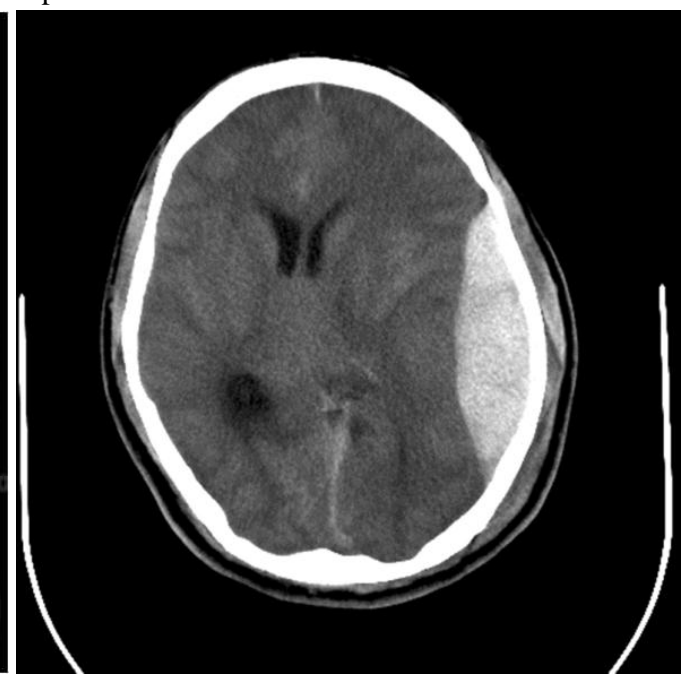

Image: 4 


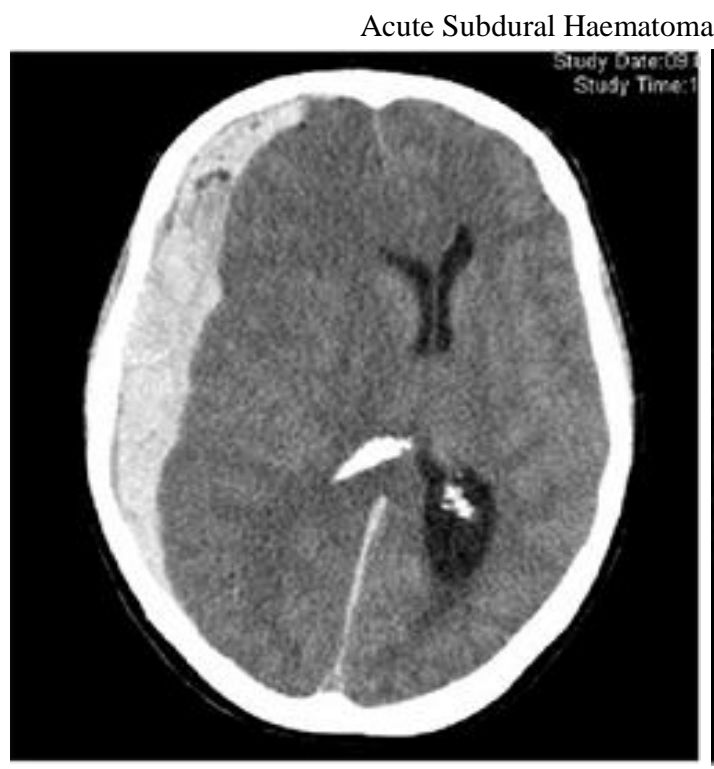

Image: 5

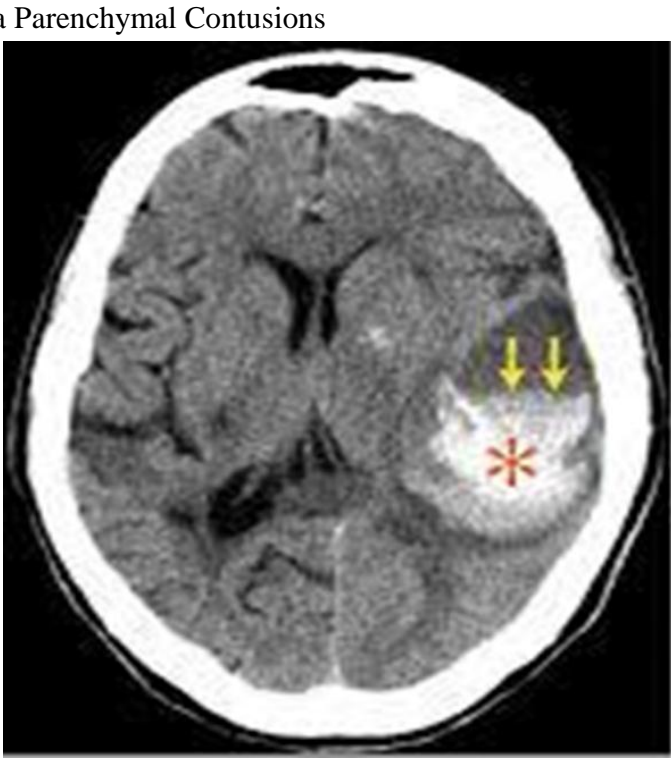

Image: 6

\section{Crescent haematoma}

\section{Results \& Discussion}

Most common cause of TBI in India is RTA (60\%) followed by falls $(25 \%)$ and assaults (10\%) as per crime bureau report. Even as per the present study, it is about the same. During 1970 - 2011 there is 7.3 times increase in road accident cases in India. Even as per the present study from $2011-2018$ there is two times increase in TBI cases from 662 in 2011 to 1142 in 2017. Common causes of TBI in the west are falls (28\%) and motor vehicle crashes (20\%), but in India it is RTA (60\%) and falls (34\%). Yet as per New Delhi study by C. Sekhar in 2014, falls are 56\% and RTA $36 \%$, and $40 \%$ of deaths occur in first 48 hours and $37 \%$ in $2-7$ days. 20Outcome in TBI in the west depends upon age but in India it is closely related to the impact of primary injury assessed by GCS.

In all the studies in India youth are most affected. As per ${ }^{22}$ central India study it is $32-64$ years age group, In the New Delhi study mean age affected is 25 years, and in other studies 15 - 35 years but as per the present study the most common age group affected is $25-50$ years. In the present study of total OP cases of 71,857and IP cases of 6532 the male: female ratio is 4.5: 1.0, head injury cases are $5723(87.61 \%)$ and cases due to falls are 2255(34.52\%). 2 - wheeler passengers are affected most often, only $3.54 \%$ used helmet and $1 \%$ used seat belt, about $20 \%$ consumed alcohol. $25.76 \%$ needed ventilator support with ICU admission indicating the severity of impact during injury. As per CT findings of 7,742 cases (both OP \& IP), $30.27 \%$ are contusions and most common and $36.82 \%$ are both SDH \& SAH, 5.8\% Diffuse Axonal Injury (DAI), and the mass effect with midline shift constitute about $14 \%$. Brain concussion is most common finding in the west but in India contusions are the most common on ct scan study.

Death rate is $3.33 \%$ of all the cases of head injury, both IP \& OP. Frontal area is affected most often (148), followed by temporal (114). Hence, frontal impact injuries are significant in TBI as per the data analysis of $677 \mathrm{CT}$ scan reports. ${ }^{21}$ Main neurosurgical operative procedures performed are Craniotomy and Evacuation of hematoma, elevation of depressed fracture and de-compression and debridement.

\section{Conclusion}

As per the data analysis of 6532 IP at the 30 bedded dedicated level one trauma care center at King George Hospital(KGH), Visakhapatnam. In this retrospective study, RTA is the most common form of all trauma and head injury is most common of it, and also the commonest cause of mortality. Young males inexperienced in driving under alcohol influence and not wearing helmet or seat belt, driving fast in the evenings or night are the usual victims of TBI. ${ }^{10,11}$ Regulated traffic control, wearing helmet and seat belt, limiting speed and avoiding $\mathrm{L} \& \mathrm{U}$ bends at road corners can ${ }^{24-29}$ prevent and minimise the incidence of fatal injuries.

\section{Financial Support: Nil.}

\section{Conflict of Interest: No.}

\section{Acknowledgement}

We are thankful to the KGH admn. for providing the data and for issuing permission to conduct the present research and also thankful to the Junior Assistat cum Data entry operator Mr. Srinivasa Rao Nammi in bringing this original research article to the final stage.

\section{References}

[1] Langlois JA, Rutland-Brown W, Thomas KE. Traumatic Brain Injury in the United States: Emergency Department Visits, Hospitalizations, and Deaths. Atlanta: Centers for Disease Control and Prevention, National center for Injury Prevention and Control; 2004.

[2] Banerjee KK, Agarwal BB, Kohli A. Agarwal NK. Study of head injury victims in fatal road traffic accidents in Delhi. Indian J Med Sci. 1998; 52(9); 395-398.

[3] Michale Johnson R. McCarthy MC, Miller SF. People JB. Craniofacial trauma in injured motorcyclists; the impact of helmet usage. J Trauma 1995; 38(6); 876-8.

[4] Gururaj G, Shastry KVR, Chandramouli AB, Subbakrishna DK, Kraus JF (2005) Traumatic brain injury. National Institute of Mental Health and neuro Sciences, Publication no. 61. 
[5] Dandona R, Mishra A. Death due to road traffic crashes in Hyderabad city in India: Need for strengthening.

[6] Pruthi N, Ashok M, Kumar VS, Jhavar K, Sampath S, Devi BI. Magnitude of pedestrian head injuries and fatalities in Bangalore, south India: A retrospective study from an apex neurotrauma center. Indian J Med Res. 2012; 136:1039-43.

[7] Gururaj G, Kolluri SV, Chandramouli BA, Subbakrishna DK, Kraus JF. Traumatic Brain Injury.Bangalore: National Institute of Mental Health and Neurosciences; 2005. [Last accessed on 2014 May 19].

[8] Ross DE. Review of longitudinal studies of MRI brain volumetry in patients with traumatic brain injury. Brain Inj. 2011; 25:1271-8.

[9] Road Accidents in India 2011. Ministry of Road Transport and Highways, Government of India. [Last accessed on 2015 Apr 02].

[10] Samabasivan M. Epidemiology of Neurotrauma. Neurology and Prevention. Neurol India (Supl) 1991; 43:9-15.

[11] Ramamurthi B. Road accidents, Epidemiology and Prevention. Neurol India (Supl) 1991; 43:9-15.

[12] Geneva: World Health Organization. (2002) Projections of Mortality and Burden of Disease to 2030: Death by Income group. 12/01/06.

[13] Gururaj G. Epidemiology of traumatic brain injuries: Indian scenario. Neurol Res. 2002; 24:24-8.

[14] Puvanachandra P, Hyder AA. The burden of traumatic brain injury in Asia: A call for Research. Pak J Neurol Sci. 2009; 4:27-32.

[15] Verma PK, Tewari KN. Epidemiology of Road Traffic Injuries in Delhi: Result of a survey: Regional health forum. WHO South-East Asia Region. 2004; 8:1-10.

[16] Luerssen TG, Klauber MR, Marshall LF. Outcome from head injury related to patients's age. A longitudinal prospective study of adult and pediatric head injury. J Neurosurg. 1988; 68:409-16.

[17] Galbraith S. Head injury in the elderly. Brit Med J (Clin Res Ed) 1987; 294:325.

[18] Waxman K, Sundine MJ, Young RF. Is early prediction of outcome in severe head injury possible? Arch Surg. 1991; 126:1237-42.

[19] Gaddis GM, Gaddis ML. Non-normality of distribution of Glasgow Coma Scores and revised Trauma Scores. Ann Emerg Med. 1994; 23:75-80.
[20] Mushkudiani NA, Engel DC, Sterberg EW, Butcher I, Juan LU, Marmarou A, et al. Prognostic values of Demographic Characteristics in Traumatic Brain Injury: Results from the IMPACT study. J Neurotrauma. 2007; 24:259-69.

[21] Mahapatra AK. Current management of head injury. Neurosci Today. 1997; 1:197-204.

[22] Bhole AM, Potode R, Agarwal A, Joharapurkar SR. Demographic profile, clinical presentation, management options in cranio-cerebral trauma: An experience of a rural hospital in central India. Pak J Med Sci. 2007; 23:724-7.

[23] Mamelak AN, Pitts LH, Damron S. Predicting survival from head trauma 24 hours after injury: A practical method with therapeutic implications. J Trauma. 1996; 41:91-9.

[24] Young T, Torner JC, Sihler KC, Hansen AR, Peek-Asa C, Zwerling C. Factors associated with mode of transport to acute care hospitals in rural communities. J Emerg Med. 2003; 24:189-98.

[25] Mock C. Improving pre-hospital trauma care in rural areas of low-income countries. J Trauma. 2003; 54:1197-8.

[26] Dandona R, Mishra A. Death due to road traffic crashes in Hyderabad city in India: Need for strengthening surveillance Natl Med J India 2004; 17:74-9.

[27] Epidemiology of road traffic accident in Hyderabad deccan, Andhra Pradesh, India.

[28] World Health Organisation Collaborating Centers for Neurotrauma, World Health Organisation; Geneva: 1995, Prevention, Critical Care and Rehabilitation of Neurotrauma-Perspectives and Future Strategies.

[29] Jha N., Srinivasa D.K., Roy G., Jagdish S. Epidemiological study of road traffic accident cases: a study from South India, Ind J Community Medicine. 2004; 29(1):20-24.

[30] Krug E., Silcock D., Ward D., Bliss A. World Health Organisation: Geneva: 2006, Helmets: A road Safety Manual for Decision Makers and Practitioners.

[31] Dinh-Zarr T.B., Sleet D.A., Shults R.A. Reviews of evidence regarding interventions to increase the use of safety belts, Am J Prev Med. 2001. 21(suppl 4):48-65.

[32] Zaza S., Sleet D.A., Thompson r.S., Sosin D.M., bolen J.C. Reviews of evidence regarding interventions to increase use of child safety seats. 